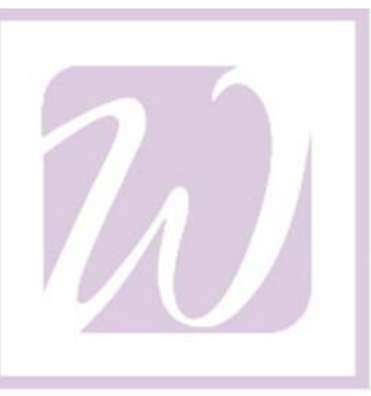

UW-WHITEWATER.

\title{
Temporal Aggregation and Purchasing Power Parity Persistence
}

$$
\text { By }
$$

Yamin Ahmad, UW-Whitewater William Craighead, Wesleyan University

Working Paper 10 - 01

University of Wisconsin - Whitewater

Department of Economics

4304 Hyland Hall

800 W. Main Street

Whitewater, WI 53538

Tel: (262) $472-1361$ 


\title{
Temporal Aggregation and Purchasing Power Parity Persistence
}

\author{
By \\ Yamin Ahmad, University of Wisconsin-Whitewater* \\ William D. Craighead, Wesleyan University ${ }^{\dagger}$
}

\begin{abstract}
This paper uses a unique new monthly US-UK real exchange rate series for the January 1794 - December 2009 period to reexamine the academic debate over purchasing power parity (PPP). The consensus view described by Rogoff (1996) is that PPP holds in the long-run, but short run deviations are very persistent, with half-lives ranging from 35 years. Most of the literature using long time series relies on the annual data developed by Lee (1976) and Lothian and Taylor (1996), which were both constructed from underlying higher-frequency data sources. Estimates of purchasing power parity persistence using these series may therefore be subject to temporal aggregation bias. We find evidence of aggregation bias which indicates the half-life of PPP deviations has been overestimated in much of the previous literature. We also find that estimates of the half-lives under temporal aggregation are further reduced once we account for the Harrod (1933)-Balassa (1964) - Samuelson (1964) effect. The result of aggregation bias appears to be robust even when considering the case that real exchange rates exhibit nonlinear dynamics.
\end{abstract}

JEL: F31, C22

Keywords: Temporal Aggregation, Real Exchange Rates, Purchasing Power Parity, Exchange Rate Persistence, Half-Lives

Current Version: February 28, 2011

\footnotetext{
* Contact Information: Department of Economics, 800 W Main Street, Whitewater, WI 53190. Tel: +1 (262) 472 5576; Email: ahmady@uww.edu

${ }^{+}$Contact Information: Department of Economics, 238 Church Street, Middletown, CT 06457. Tel: +1 (860) 685 5784; Email: bcraighead@wesleyan.edu
} 


\section{Introduction}

During the course of the last two decades, a large body of literature has been devoted to characterizing and understanding the dynamics of real exchange rates. A number of these studies have used time series of real exchange rates spanning a century or more in order to test the Purchasing Power Parity (PPP) hypothesis. The use of such long series has been motivated, in part, by the difficulty of rejecting the random walk hypothesis in samples limited to the post-Bretton Woods floating rate era. As is more commonly understood now, the inability to reject a random walk was largely due to the low power of standard unit root tests. This has been documented by Lothian and Taylor (1997), among others. The use of longer data series has helped to rehabilitate the PPP hypothesis and arrive at what Rogoff (1996) described as a "consensus" that PPP deviations have a half-life of 3-5 years.

However, many of the studies underpinning this consensus utilize annual frequency data sets that were assembled by averaging underlying higher-frequency series. Working (1960) showed that such temporal aggregation creates a bias, leading to overestimates of persistence. Taylor (2001) made a theoretical argument that this problem has afflicted the empirical literature on PPP.

In this paper, we utilize a new 216-year monthly frequency data series of the US-UK real exchange rate assembled by Craighead (2010) to examine the implications of temporal 
aggregation for estimates the persistence of PPP deviations. We show that estimated half-lives of PPP deviations are substantially lower in monthly data than in quarterly and annual data created by averaging the monthly series, which provides empirical confirmation of Taylor's hypothesis. This remains true even after accounting for two other factors that have been shown to impact the estimated persistence of deviations: time-varying equilibria and nonlinearities ${ }^{1}$.

The standard interpretation of the PPP theory implies stationarity of the real exchange rate. However, the well-known hypothesis of Harrod (1933), Balassa (1964) and Samuelson (1964) suggests that a country's real exchange rate will appreciate as it develops, which implies the long-run equilibrium may vary over time. The empirical relevance of the Harrod-Balassa-Samuelson (HBS) effect for purchasing power parity has previously been demonstrated by Lothian and Taylor (2008) and Chong, Jorda and Taylor (2010). We find that the speed of convergence to equilibrium increases further when the HBS effect is accounted for.

Taylor (2001) also noted that the use of linear models potentially creates another source of overestimated persistence of PPP deviations. An extension to a nonlinear framework for the current floating rate period illustrates this point, as the estimated persistence of

\footnotetext{
${ }^{1}$ Other types of bias have also been suggested in the literature examining PPP. For example, Imbs et al. (2005) examine how sectoral heterogeneity in convergence to the law of one price can cause the estimated half life to be biased upwards, although Chen and Engel (2005) do not find this source to be quantitatively important. Boyd and Smith (1999) consider lagged dependent variable bias. More recently, Crucini and Shintani (2008) suggest that the long half lives may be an artifact of using aggregated data, as opposed to micro level data.
} 
PPP deviations is shown to be lower using an exponential smooth transition (ESTAR) model. Moreover, we also find that the nonlinear model exhibits temporal aggregation bias, since the estimated persistence is also lower using monthly rather than quarterly or annual data.

To summarize, we show that reducing temporal aggregation bias by using higher frequency data, allowing for a time-varying equilibrium due to the HBS effect, and employing nonlinear estimation are complementary. Individually, all three reduce the estimated persistence of deviations from PPP, and the combined effect is a substantial increase in the speed of convergence which serves to strengthen the PPP hypothesis.

The remainder of the paper is organized as follows. Section 2 outlines the issue of temporal aggregation as it pertains to the biases that may arise when calculating halflives. A description of the data can be found in section 3 followed by initial estimates of the half-life from linear models of the real exchange rate. The HBS effect is incorporated in section 4. Section 5 then relaxes the assumption of linearity and utilizes an exponential smooth transition (ESTAR) model of real exchange rates to examine bias in estimating persistence. The final section concludes.

\section{Temporal Aggregation and Half-Life Estimation}

In a seminal article, Holbrook Working (1960) examined the biases that arose as a result of time averaging for estimates of serial correlation parameters in autoregressions 
containing price differentials. Although the issue of biases arising from temporal aggregation is well-known, relatively few studies have examined the implications for real exchange rates. Among those that have are Taylor (2001), Byers and Peel (2003), Choi, Mark and Sul (2006), and Ahmad and Paya (2011) ${ }^{2}$.

Consider the following linear AR(1) process for a dependent variable, such as the real exchange rate:

$$
y_{s}=\rho y_{s-1}+\varepsilon_{s}
$$

where $s=1, \ldots, T, \varepsilon_{s} \sim N\left(0, \sigma^{2}\right), 0 \leq \rho<1$, that is then subsequently aggregated into a lower frequency, $y_{t}^{A}$, as follows:

$$
y_{t}^{A}=\frac{1}{k}\left(y_{k(t-1)+1}+\ldots+y_{k t}\right)
$$

For example, if $k=12$, then this process would create an annual series from a monthly one. A typical way to measure the persistence of a series like the one above is to estimate the half-life of a shock. In the $A R(1)$ case this can be done by estimating a first order autoregression:

$$
y_{t}^{A}=c+\rho_{A} y_{t-1}^{A}+\varepsilon_{t}
$$

and then computing the half-life measure, $h$, as:

$$
h=\frac{k \ln 0.5}{\ln \hat{\rho}_{A}}
$$

\footnotetext{
${ }^{2}$ Interestingly, as a counterpoint, Ahmad and Paya (2011) find that in the case when the underlying data generating process driving exchange rates is a true random walk, then parameter and subsequent estimates of persistence are actually biased downwards under temporal aggregation. As such, if the unobservable factors that drive exchange rates are truly nonstationary, then current estimates of persistence and the half-life of a shock are actually understated!
} 
where $\hat{\rho}_{A}$ is the autoregressive coefficient that is estimated from equation (2). Taylor (2001) demonstrates that such calculations are biased upwards, with the bias increasing in $k$, the degree of aggregation.

If the order of autoregression $p$, is unknown, then the usual approach is to make some inference about $p$ using an information criterion, or by examining the partialautocorrelation function. If these indicate that $p>1$, then a similar process to the one above ensues, whereby the researcher would first estimate the $A R(p)$ process. However, in the case where $p>1$, an analytical solution for the half-life cannot be obtained since the persistence of the process depends on all the estimated parameters. Several methods have been suggested for calculating half-lives and we outline one that we adopt in section 3 .

\section{Half-Life Estimation}

\subsection{Data}

This study focuses on the US-UK real exchange rate, which is one of the most frequently studied series in the literature. The series requires three underlying components: price levels for the two countries and the nominal Dollar-Sterling exchange rate. The datasets most commonly used in the literature are those compiled by Lee (1976) for the period 1900-72 and Lothian and Taylor (1996; hereafter LT) which covers 1791-1990³. For

\footnotetext{
${ }^{3}$ This paper focuses on the US-UK real exchange rate; LT also examines a France-UK series, and Lee also includes real exchange rates between the US and Canada, France, Italy, Japan and the UK.
} 
prices, both utilize annual averages of underlying monthly price index series. ${ }^{4}$ The nominal exchange rate component of the Lee series is the Gold Standard parity through 1913, and annual averages from underlying daily Federal Reserve data thereafter. LT utilize exchange rates compiled by Lawrence Officer $(1983,1985)$ through 1899 , from Friedman and Schwartz (1982) for 1900-1972 and from the IMF's International Financial Statistics (IFS) thereafter through 1990. Officer's series is quarterly, though for some periods, the original data underlying it are monthly. For the relevant time period, Friedman and Schwartz (1982) report annual averages from monthly sources that, in turn, were created from daily data; for $1913-1972$ it is the same Federal Reserve data used by Lee.

Among the papers examining PPP utilizing the Lee series are Adler and Lehmann (1983), Abuaf and Jorion (1990), Glen (1992), Cheung and Lai (1994) and Murray and Papell (2002). Hedgwood and Papell (1998) use both the Lee and LT series. Murray and Papell (2005), Paya and Peel (2006) and Lothian and Taylor (2008) use the LT data. The latter two studies utilize nonlinear models. An important exception to the norm of using data aggregated to an annual level is Grilli and Kaminsky (1991), who examine a monthly USUK series over the period $1885-1986$. They reject the presence of a unit root, and utilize variance ratios to examine persistence, but they do not provide half-life estimates. Their series is also utilized by Engel and Kim (1999), who estimate a Markov switching model.

\footnotetext{
${ }^{4}$ In the case of Lothian and Taylor, this occurs indirectly since they employ Jastram's (1977) annual series, which averages underlying monthly data.
} 
This paper utilizes the data series compiled by Craighead (2010), extended through December 2009, which is plotted in figure 1. There is considerable overlap between this dataset and those of Lee and LT in their underlying sources. UK prices are drawn from Gayer, Rostow and Schwartz (1953) for 1794-1844, Klovland (1993) for 1845-1890, the Sauerbeck index for 1891-1919, and the UK wholesale price index thereafter through 2009. The US price component is from Warren and Pearson (1933) through 1913, and the BLS thereafter. The Dollar-Sterling exchange rate was constructed following the methodology of the Lawrence Officer series used by LT, but a change in underlying sources allowed construction of a monthly series. For 1794-1834, the basis of the series is bills of exchange prices reported to Congress by the Treasury department, and for 1835-1878, Martin (1898). For 1879-1913, the exchange rates are monthly averages of the daily data constructed by Canjels, Prakash-Canjels and Taylor (2004) and thereafter the data is from the Federal Reserve.

Although the Dollar-Sterling exchange rate has undergone a number of changes in the nominal exchange rate regime during its history, Lothian and McCarthy (2002) show that nominal regimes do not significantly affect the speed of adjustment, so we focus our attention on the series as a whole. For a more detailed examination of the various regimes and an investigation of how other properties of the series have varied across regimes and time, see Craighead (2010). 


\subsection{Results for the Linear Case}

Panel A of Table 1 reports results from the $A R(1)$ regression

$$
q_{t}=c+\rho q_{t-1}+\varepsilon_{t}
$$

where the log real exchange rate, $q$, is defined in relation to the log nominal US Dollar UK Sterling exchange rate and respective log price levels as follows:

$$
q_{t}=e_{t}+p_{t}^{U K}-p_{t}^{U S}
$$

Following LT, the standard errors are calculated in a heteroskedasticity-robust manner due to the differences in volatility among the regime periods covered by the sample.

The results in panel A of Table 1 compares those from the monthly data to estimates from data aggregated to quarterly and annual frequencies by temporal aggregation in the form of time averaging. For the entire 216-year sample, the averaged data yields a half-life estimate of 46.8 months, a year longer than the estimate of 34.6 months given by the monthly series. This provides empirical evidence that aggregation bias has indeed led to an overstatement of persistence in the previous literature.

Taylor (2001) derived a formula to predict the degree of aggregation bias in $A R(1)$ estimates of half-lives. Taylor's formula gives the predicted half-life, $h_{p}$, from an underlying series with an autoregressive coefficient of $\rho$ aggregated to the $k^{\text {th }}$ degree as:

$$
h_{p}=\frac{k \ln 2}{\ln \left[k\left(1-\rho^{2}\right)-2 \rho\left(1-\rho^{k}\right)\right]-\ln \left[\rho\left(1-\rho^{k}\right)^{2}\right]}
$$


According to this formula, an underlying monthly series with a half-life of 34.6 months would yield an estimated half-life of 52.8 months after being aggregated to an annual series. This is slightly more than the 46.8 months estimated using this particular series. This shows that, while the aggregation bias is clearly substantial in studies using the USUK series, in practice it is not quite as large as Taylor's calculation would indicate.

The examination of persistence can be extended by relaxing the assumption of an $A R(1)$ process. If the variable of interest, $y_{t}$, follows an $A R(p)$ process such as:

$$
y_{t}=\beta_{0}+\sum_{j=1}^{p} \beta_{j} y_{t-j}+\varepsilon_{t}
$$

this can be conveniently reparameterized into an augmented Dickey-Fuller regression and written as:

$$
y_{t}=\alpha+\lambda y_{t-1}+\sum_{j=1}^{p-1} \delta_{j} \Delta y_{t-j}+\varepsilon_{t}
$$

where $\lambda=\sum_{j=1}^{p} \beta_{j}$ and $\delta_{j}=-\sum_{i=1+j}^{p} \beta_{i}$. The key parameters which determine the persistence of the series are $\lambda$ and $\delta_{j}, j=1, \ldots, p-1$. Consequently, for an AR(p) process, there is no simple expression that can be written for the half-life. We start by choosing the order of the autoregression, $p$, with a view towards favoring parsimony, by using the AIC and SBC information criteria as well as by examining the partial autocorrelation function. Having selected $p$ we then ensure that there is no remaining autocorrelation in the residuals by computing the Q-statistics from a Ljung-Box (1979) test. The estimates of equation (6) are reported in the first three columns of Table 2, where $y_{t}=q_{t}$. The next step is then 
to calculate the half-life. We report the results of three alternative approaches within panel A of Table 3. The first, suggested by Rossi (2005), involves computing a measure such as:

$$
\tilde{h}=\frac{\ln (0.5 / b)}{\ln \hat{\rho}}
$$

where $b$ represents a factor that can control for bias when estimating the half life for near-unit root processes in linear univariate models. In effect, Rossi's (2005) approach utilizes the value of the largest autoregressive root. The second approach is one that is suggested by Andrews (1993) and Andrews and Chen (1994) and it involves computing the half-life using the sum of the autoregressive coefficients, instead of the coefficient on the $A R(1)$ term, i.e.

$$
\tilde{h}=\frac{\ln (0.5)}{\ln \lambda}
$$

In the case of an $\operatorname{AR}(1)$ process, $b=1$ and and $\lambda=\rho$, so both measures of the half-life above equal the traditional measure of the half-life in the $A R(1)$ case; however, for higher order AR processes, the two measures suggested by Rossi (2005) and Andrews and Chen (1994) above will differ from the one used for an AR(1) process. One drawback of these two approaches is that the methods are suggested to compute half-lives for linear models. Thus, we also report the results from a third approach suggested by Dias and Marques (2010) and Mark (2001), which involves computing the half-life directly from an impulse response function, since the rate at which a shock is absorbed depends directly on the autocorrelation coefficients. Since we estimate and examine mean 
reversion from an ESTAR model of the real exchange rate for the current floating period later in this paper, we utilize the Generalized Impulse Response Function (GIRF) for nonlinear models that was developed by Koop, Pesaran and Potter (1996), so that we can maintain consistency between the linear and nonlinear cases that we examine. Consequently, we can compute a measure of the half-life in the nonlinear case by examining the decay pattern of an impulse. Regardless of the approach, our final estimate of the half-life in the aggregated cases are calculated as: $h=k \tilde{h}$, as in equation (3).

\section{Computing Generalized Impulse Response Functions}

Although the GIRF and the traditional IRF coincide for linear models, the advantage of the GIRF over a traditional impulse response function lies in its ability to account for a number of properties that do not translate from linear models to nonlinear models. In particular, a traditional impulse response function calculated from a nonlinear model would exhibit history and shock dependence (see Koop et al., 1996, for details). The GIRF methodology proposed by Koop et al. (1996) uses Monte Carlo integration to integrate out these dependencies. The GIRF is defined as the average difference

between two realizations, or sample paths, of a stochastic process $\left\{y_{t+n}\right\}$ that are hit by exactly the same random set of shocks except at one particular point in time:

$$
\operatorname{GIRF}_{n}\left(n, \theta, \omega_{t-1}\right)=E\left(y_{t+n} \mid v_{t}=\theta, \omega_{t-1}\right)-E\left(y_{t+n} \mid v_{t}=0, \omega_{t-1}\right)
$$


where $n=1,2, \ldots$, denotes the horizon, $v_{t}=\theta$ is an arbitrary shock that occurs at time $t$, and $\omega_{t-1}$ denotes the history of the process $\left\{y_{t}\right\}$. Thus these sample paths have an identical history up to some point in time, $t-1$, but at time $t$, one realization is perturbed by a shock whereas the other realization for the process is not.

We use stochastic simulation to approximate the function given in equation (7), since an analytical expression cannot be constructed for $n>1$, as equation (7) is a realization of a random variable (see Koop et al., 1996). We condition on all past histories, where for each history, we generate 1000 sample paths of $y_{t}$, i.e., $\hat{y}_{0}^{*}, \ldots, \hat{y}_{n}^{*}$, based on the two time profiles where $v_{t}=\ln \left(1+\frac{\psi}{100}\right)$ along one path and $v_{t}=0$ along the other. We chose $\psi=20$ to represent a 20 percent shock to the level of the real exchange rate. The difference between the two paths is averaged across all replications and stored. In the ESTAR model that we estimate later, we do this for all possible histories and average across the histories to integrate out history dependence, given the nonlinear nature of the ESTAR framework. Once we have obtained the GIRF, we obtain $\lambda$-lives by computing the number of periods that it takes for the initial shock seen in the impulse response function to dissipate by $100 \lambda$ percent.

The results reported in panel A of Table 3 provide fairly strong evidence of the presence of aggregation bias. In general the aggregated quarterly and annual data yields longer estimated half-lives than in the underlying monthly data. Although the point estimates 
of the half-life based on Rossi's (2005) bias correction procedure yield lower values of the half-life for the quarterly and annually aggregated data, when the confidence intervals for the half-life are taken into account, the coverage shows that the range of values at the $95 \%$ level for the monthly data lie below those for the quarterly and annual data. Both the point estimates and the confidence intervals for the half-life based on the method by Andrews (1993) and Andrews and Chen (1994) show lower values of the half-life for the monthly when compared to quarterly and annually averaged data. Finally, the estimates of the $\lambda$-life based on the generalized impulse response functions show a reduction in the estimated half-life using monthly data. This is also true when the time to decay of 25 percent and 75 percent are considered. In the entire sample, this method yields a half-life of 44.5 months for annual data, versus 33.7 months in monthly data, which implies the rate of decay is outside the range implied by Rogoff's (1996) "consensus."

One implication of the PPP hypothesis is that $q_{t}$ should be a stationary time series. Unit root tests therefore provide a means of formally testing for PPP. As noted above, the low power of unit root tests in short series has motivated research using longer data spans. Table 4 reports the t statistics generated by the standard augmented DickeyFuller and Phillips-Perron unit root tests. The null hypothesis of a unit root is strongly rejected at the monthly, quarterly and annual frequency using the longer time series data. 


\section{Allowing for Time-Varying Equilibria}

As noted above, the equilibrium real exchange rate may evolve over time due to the HBS effect, which predicts higher relative price levels for more developed countries. To understand this, consider a country's price level, $P$, as a geometric average of traded and nontraded goods prices, $P_{T}$ and $P_{N}$, respectively. That is,

$$
P=P_{N}^{\gamma} P_{T}^{1-\gamma}
$$

which can be written in logs as

$$
p=\gamma p_{N}+(1-\gamma) p_{T}
$$

In competitive economies, wages are equal to the value marginal product of labor, and labor mobility equates wages between sectors. This implies the price of nontraded relative to traded goods should be inversely related to relative productivity. That is, in logs,

$$
p_{N}-p_{T}=z_{T}-z_{N}
$$

where $z_{T}$ and $z_{N}$ represent traded and nontraded sector productivity, respectively. Applying this to the real exchange rate equation (4) yields

$$
q=e+p_{T}^{U K}-p_{T}^{U S}+\gamma\left(z_{T}^{U K}-z_{T}^{U S}\right)-\gamma\left(z_{N}^{U K}-z_{N}^{U S}\right)
$$

If traded goods are equated by the law of one price and if technological progress occurs largely through the traded goods sector, this implies that the dynamics of the real exchange rate will be driven by the evolution of $z_{T}^{U K}-z_{T}^{U S}$.

Because sectoral productivity data are unavailable, data on per capita GDP are used as a proxy. For the US, these data are taken from the Historical Statistics of the United 
States through 2000, and the Bureau of Economic Analysis and Census Bureau thereafter. The UK series is created using the data from Maddison's Historical Statistics of the World Economy, beginning with 1830 . Prior to 1830 , the series is a backward extrapolation using the average growth rates estimated by Crafts (1985). Because the HBS effect describes a long-run relationship, the cyclical components are removed using the Hodrick-Prescott filter. ${ }^{5}$ The resulting annual trend component series are then interpolated to create a monthly series. The percentage gap between US and UK trend real per capita GDP is shown in figure 2. At the beginning of the period, the UK had a higher per capita GDP than the US, but this gap began to narrow in the late nineteenth century. The UK fell increasingly behind the US during the first half of the twentieth century, particularly during the Second World War.

To account for the HBS effect, the $A R(1)$ regression equation is augmented as follows:

$$
q_{t}=c+\rho q_{t-1}+\mu h_{t}+\varepsilon_{t}
$$

where $h_{t}$ is the log difference between UK and US trend per capita real GDP. Results are reported in panel B of Table 1. At all three frequencies considered, the coefficient on the HBS effect term is statistically significant. Incorporating the HBS effect results in another substantial reduction in implied half-lives - from 34.6 to 28.1 months in monthly data. Furthermore, we also account for the HBS effect in the AR(p) case, by augmenting the HBS effect into equation (6) as follows:

\footnotetext{
${ }^{5}$ Although we report the results using a value of 400 for the smoothing parameter in the HP filter, we find similar results when the parameter equals 100 .
} 


$$
y_{t}=\alpha+\mu h_{t}+\lambda y_{t-1}+\sum_{j=1}^{p-1} \delta_{j} \Delta y_{t-j}+\varepsilon_{t}
$$

The order of autoregression is determined as has been previously described, and the estimates of the parameters in the equation above are reported in the last three columns of Table 2. As in the prior case without the HBS term, the parameters are all statistically significant at the $5 \%$ level and the Ljung-Box Q statistics demonstrate that the estimated model has adequate fit. The estimates of the half-life based on the three measures that we examine are reported in panel B of Table 3. As in the $A R(1)$ case, the estimates of the half-life are substantially reduced once the HBS effect is accounted for. In addition, there is fairly strong evidence in favor of the bias resulting from temporal aggregation. Although Rossi's (2005) approach yields a smaller estimate of the half-life for the quarterly and annual frequencies, both of the other two approaches we utilize consistently yield smaller values of the half-life at the monthly frequency. Overall, we take the evidence from the $A R(p)$ case to be suggestive of a bias resulting from temporal aggregation.

In order to test for the stationarity of the real exchange rate series after adjusting for the HBS effect, we run the following regression:

$$
q_{t}=c+\beta h_{t}+\varepsilon_{t}
$$

The resulting regression coefficient is then used to generate a HBS-adjusted series,

$$
q_{t}^{A}=q_{t}-\hat{\beta} h_{t} .
$$


Unit root test results for the adjusted series are reported in Table 4. Once the HBS effect is incorporated, the unit root hypothesis is even more strongly rejected at all frequencies.

\section{Half-Life Estimates from an ESTAR Framework}

In this section, we relax the assumption of linearity, and instead consider the impact of temporal aggregation on estimates of half-lives within a framework where real exchange rates exhibit nonlinear dynamics. The examination of nonlinear dynamics has been motivated by transactions costs (e.g., Michael, Nobay and Peel, 1997), heterogeneity of agent beliefs (e.g., Killian and Taylor, 2003) and, more recently, misalignments in the foreign exchange market leading to a lack of coordination among market participants (e.g., Reitz and Taylor, 2008). Although different studies have captured the nature of nonlinear dynamics in a variety of ways, threshold models have become widespread in application to real exchange rates. In particular, the exponential smooth transition autoregressive (ESTAR) framework has been found to be successful in being able to parsimoniously capture the dynamics of real exchange rates.

ESTAR models have the prediction that the dynamics of real exchange rates are nonlinear but globally stationary, rather than linear stationary. Within an ESTAR framework, real exchange rates have the ability to adjust their dynamic behavior depending on how much the real exchange rate deviates from PPP. Consequently, deviations from PPP can be written as: 


$$
y_{t}=k+\sum_{j=1}^{p} \theta_{j} y_{t-j}+\left(k^{*}+\sum_{j=1}^{p} \theta_{j}^{*} y_{t-j}\right) F\left(\gamma, y_{t-d}\right)+\varepsilon_{t}
$$

where the sequence of deviations from PPP, $y_{t} \equiv q_{t}-h_{t}$, is a stationary, ergodic process, $\varepsilon_{t} \sim \operatorname{iid}\left(0, \sigma^{2}\right)$ and $\gamma \in[0,+\infty) . \mathrm{F}(\cdot)$ represents the transition function from one regime to another and it determines the degree of mean reversion. Since economic intuition suggests that both positive and negative deviations from PPP would have symmetric effects on mean reversion, the ESTAR model posits that the transition function exhibits an exponential form as follows:

$$
F\left(\gamma, y_{t-d}\right)=1-\exp \left[-\gamma\left(y_{t-d}-c_{0}\right)^{2}\right]
$$

which has the following properties: $F:[0, \infty) \rightarrow[0,1], F(0)=0, \lim _{x \rightarrow \pm \infty} F(x)=1$ and is symmetric around zero. As such, the inner regime of the model represented by equation (10) above occurs where $F(\cdot)=0$, and the model becomes a linear $A R(p)$ model of the form:

$$
y_{t}=\sum \theta_{j} y_{t-j}+\varepsilon_{t}
$$

The outer regime corresponds to $\lim y_{t-d} \rightarrow \pm \infty$ where $\mathrm{F}(\cdot)=1$, and hence equation (10) becomes a different $A R(p)$ model of the form:

$$
y_{t}=\left(k+k^{*}\right)+\sum\left(\theta_{j}+\theta_{j}^{*}\right) y_{t-j}+\varepsilon_{t}
$$

As earlier for the linear case, reparameterizing the ESTAR model in equation (10) into an augmented Dickey-Fuller regression yields:

$$
\Delta y_{t}=\tilde{\lambda} y_{t-1}+\sum_{j=1}^{p} \phi_{j} \Delta y_{t-j}+\left(\lambda^{*} y_{t-1}+\sum_{j=1}^{p} \phi_{j}^{*} \Delta y_{t-j}\right) \times F\left(\gamma, y_{t-d}\right)+\varepsilon_{t}
$$


The parameters which determine the degree of persistence are $\tilde{\lambda}$ and $\lambda^{*}$. If any evidence of nonstationary behavior exists, either $\tilde{\lambda}$ or $\lambda^{*}$ will be greater than zero. However, if the outer regime is stationary and the inner regime nonstationary, then we must have $\lambda^{*}<0$ and $\tilde{\lambda}+\lambda^{*}<0$. In other words, if deviations from PPP are small, then $y_{t}$ may exhibit nonstationary or random walk type behavior, while large deviations from PPP would yield a mean reverting process for $y_{t}$, as predicted by PPP.

We implement the method outlined in Teräsvirta (1994) for estimating the ESTAR model. This first involves determining the order of autoregression, $p$. We use the same approach to determine $p$ that was used for the linear case. The next steps subsequently involve testing for linearity and selecting the value of the delay parameter, $d$, based on a Taylor expansion of the transition function around $\gamma=0$. Finally, once a specification has been determined, the appropriate model is estimated through nonlinear least squares. $^{6}$

Because the ESTAR model has been shown to parsimoniously capture the dynamics of real exchange rates for the current floating period in several recent studies mentioned earlier, in this section we focus on the period beginning with the collapse of Bretton Woods in August, 1971. Furthermore, Ahmad and Glosser (2009), point out that the

\footnotetext{
${ }^{6}$ A final step prior to model estimation involves choosing between an LSTAR and ESTAR specification (the reader is referred to Teräsvirta, 1994, for the specific details of the estimation methodology). In addition, we also employ an alternative method for choosing between an LSTAR and ESTAR specification, which was proposed by Escribano and Jorda (2001).
} 
ESTAR model may not be appropriate for every single period in terms of its ability to capture the true nature of the nonlinear dynamics.

An ESTAR model is predicted using Teräsvirta's (1994) method for the current floating period at monthly, quarterly and annual frequencies. Our results here confirm the findings of Paya and Peel (2006) who use Monte Carlo simulations to show that ESTAR type of nonlinearity is preserved under temporal aggregation. ${ }^{7}$ Table 5 provides details of the results of the linearity test and the value of the delay parameter, $d$, that was selected using Teräsvirta's (1994) methodology to estimate the ESTAR model. We report results both including the HBS term and without it.

Having estimated the model through nonlinear least squares, we then implement the GIRF procedure of Koop et al. (1996) outlined earlier, to calculate the $\lambda$-life of a shock. Given the nonlinear framework of the ESTAR model, the value of the shock is of importance. If a shock to the level of the real exchange rate is small, then it may be insufficient to move the real exchange rate beyond its threshold and thus the real exchange rate may lie within the inner regime. As such, estimates of the half-life within the inner regime are likely to be very large, given the nonstationary nature of the inner regime. In particular, the GIRF may not be monotonic in this case. Alternatively a shock to the real exchange rate that is sufficiently large, would move the real exchange rate beyond its threshold. As such, given the globally stationary nature of the ESTAR

\footnotetext{
${ }^{7}$ A key difference between our paper and that of Paya and Peel (2006) is that we can confirm their finding in actual data. Paya and Peel (2006) show the result through simulations.
} 
framework, this would lead to an estimate of the half-life for the mean reverting regime, where the GIRF would exhibit monotonic behavior. Therefore, we calculate the half-life for a two-standard deviation shock to the level of the real exchange rate, which was sufficient to move the real exchange rate to the outer regime in all the cases that we examined. This can be seen in the generalized impulse responses that are plotted in figure 3.

The results of the $\lambda$-life calculated from the GIRF are reported in Table 6 . For all the estimated frequencies, i.e., monthly, quarterly and annual frequencies, accounting for nonlinearities reduces the estimated persistence vis-à-vis the linear model estimates reported in tables 1 and 2. At the monthly frequency, the ESTAR model yields a half life of 22.8 months when no HBS term is included, compared to 33.7 months from an AR(3) model and 34.6 months in an AR(1) model. Once the HBS term is included, we see a further reduction in the estimated half-life from 28.1 months in the AR(1) case, to 27.2 months in the $A R(3)$ case, to 19.9 months in the ESTAR case. We find similar results at the quarterly and annual frequencies.

Our results indicate that temporal aggregation may substantially affect the results in nonlinear as well as linear models. The nonlinear estimates of $\lambda$-lives are substantially lower when monthly data is used in place of both quarterly and annual data. This is consistent with the findings of Paya and Peel's (2006) examination of the effects of 
temporal aggregation in an ESTAR context. Moreover, the results are robust to the inclusion of the HBS term.

\section{Conclusion}

The persistence of deviations from purchasing power parity has been the subject of considerable controversy in the literature on real exchange rate behavior. Taylor (2001) describes two competing "teams" of scholars, one which is "whittling down half-lives" while the other is "whittling up half-lives." The results of this paper lend support to the "whittling down" squad, as the use of a new monthly data series has confirmed the empirical relevance of temporal aggregation bias through time averaging in the widelystudied historical US-UK real exchange rate. This suggests previous estimates of persistence made using annual data are overstated.

Moreover, our results indicate that the estimated persistence is reduced further by accounting for the nonlinearities contained within the data and the possibility of a time varying equilibrium due to the HBS effect. The effect of aggregation bias is robust to these extensions and the cumulative effect is a substantial reduction of the estimated half-life. The "consensus" view about the persistence of deviations should be updated to reflect the fact that convergence to PPP occurs more quickly than previously believed. 


\section{References}

Abuaf, Niso and Philippe Jorion (1990), "Purchasing power parity in the long run", Journal of Finance, 45, pp. 157-174.

Adler, Michael and Bruce Lehmann (1983), "Deviations from purchasing power parity in the long run", Journal of Finance, 38, pp. 1471-1487.

Ahmad, Y. and Glosser, S. (2009), "Searching for nonlinearities in real exchange rates", Applied Economics, iFirst, May 2009, pp. 1 - 17.

Ahmad, Y. and Paya, I. (2011), "Temporal Aggregation of Unit Root Processes and Implications for Asset Prices?", mimeo

Andrews, D. (1993), "Exactly Median-Unbiased Estimation of First Order Autoregressive/Unit Root Models", Econometrica, 61(1), pp. 139 - 165.

Andrews, D. and H-Y. Chen (1994), "Approximately Median-Unbiased Estimation of Autoregressive Models", Journal of Business and Economic Statistics, 12(2), pp. 187 204.

Balassa, B. (1964), "The purchasing-power parity doctrine: a reappraisal," Journal of Political Economy, 72, pp. 584-96.

Boyd, D. and R. Smith (1999), "Testing for Purchasing Power Parity: Econometric Issues and an Application to Developing Countries", The Manchester School, 67(3), pp. 287 303.

Byers, J. D. and D. A. Peel (2003), "Another example of a non-linear time series with misleading linear properties", Applied Economics Letters, 10, pp. $47-51$.

Canjels, E., G. Prakash-Canjels and A.M. Taylor (2004), "Measuring Market Integration: Foreign Exchange Arbitrage and the Gold Standard, 1879-1913" Review of Economics and Statistics $86,868-882$

Chen, S. and C. Engel (2005), “Does 'Aggregation Bias' Explain the PPP puzzle?", Pacific Economic Review, 10, pp. $49-72$.

Cheung, Yin-Wong and Kon S. Lai (1994), "Mean reversion in exchange rates", Economics Letters, 46, pp. 251-256.

Choi, C., N. Mark and D. Sul (2006), "Unbiased Estimation of the Half-Life to PPP Convergence in Panel Data", Journal of Money Credit and Banking, 38, pp. 921 - 938.

Chong, Y., O. Jorda and A. Taylor (2010), "The Harrod-Balassa-Samuelson Hypothesis: Real Exchange Rates and Their Long-Run Equilibium," NBER Working Paper 15868. 
Crafts, N.F.R., (1985), British Economic Growth during the Industrial Revolution, Oxford: Clarendon Press.

Craighead, W. (2010), “Across Time and Regimes: 212 Years of the US-UK Real Exchange Rate", Economic Inquiry, 48(4), 951-964.

Crucini, M. and M. Shintani (2008), "Persistence in law of one price deviations: Evidence from micro data", Journal of Monetary Economics, 55, pp. 629-644.

Dias, D. and C. R. Marques (2010), "Using Mean Reversion as a Measure of Persistence", Economic Modelling, 27(1), Jan. 2010, pp. 262 - 273

Engel, Charles and Chang-Jin Kim (1999), "The Long Run U.S./U.K. Real Exchange Rate", Journal of Money Credit and Banking, Vol. 31. No. 3, (August), pp. 335 - 356.

Escribano, A. and O. Jorda (2001), "Testing nonlinearity: Decision rules for selecting between logistic and exponential STAR models", Spanish Economic Review, Vol. 3, pp. $193-209$.

Friedman, Milton and Anna J. Schwartz (1982), Monetary trends in the United States and United Kingdom, University of Chicago Press: Chicago.

Gayer, A.D., W.W. Rostow and A. J. Schwartz (1953), The Growth and Fluctuation of the British Economy 1790-1850. Oxford: Clarendon Press.

Glen, Jack D. (1992), "Real exchange rates in the short, medium and long run", Journal of International Economics, 33, 1992.

Grilli, Vittorio and Graciela Kaminsky (1991), "Nominal exchange rate regimes and the real exchange rate", Journal of Monetary Economics, 27, pp. 191-212.

Harrod, R., (1933), International Economics, London: Nisbet and Cambridge University Press

Hedgwood, Natalie D. and David H. Papell (1998), "Quasi purchasing power parity", International Journal of Finance and Economics, 3, pp. 279-289.

Imbs, J., H. Mumtaz, M. Ravn, and H. Rey (2005), “PPP Strikes Back: Aggregation and the Real Exchange Rate", Quarterly Journal of Economics, 120. pp. 1 - 43.

Jastram, Roy W. (1977), The golden constant, John Wiley and Sons: New York.

Kilian, L. and M. P. Taylor (2003), "Why is it so difficult to beat the random walk forecast of exchange rates?", Journal of International Economics, 60, pp. 85 - 107. 
Koop, Gary M., H. Pesaran and Simon M. Potter (1996), "Impulse response analysis in nonlinear multivariate models", Journal of Econometrics, 74, pp. 119-147.

Klovland, J.T. (1993), "Zooming in on Sauerbeck: Monthly Wholesale Prices in Britain 1845-1890," Explorations in Economic History 30, 195-228.

Lee, Moon H. (1976), Purchasing power parity, Marcel Dekker: New York.

Lothian, James R. and Cornelia H. McCarthy (2002), "Real Exchange Rate Behaviour Under Fixed and Floating Exchange Rate Regimes," The Manchester School, 70(2), pp. 229-245.

Lothian, James R. and Mark P. Taylor (1996), "Real exchange rate behavior: the recent float from the perspective of the past two centuries", Journal of Political Economy, 104, pp. 488-509.

Lothian, James R. and Mark P. Taylor (1997), "Real exchange rate behavior", Journal of International Money and Finance, 16, pp. 945-954.

Lothian, James R. and Mark P. Taylor (2008), "Real Exchange Rates Over The Past Two Centuries: How Important is the Harrod-Balassa-Samuleson Effect", The Economic Journal, Vol. 118, (October), pp. $1742-1763$.

Ljung, G. and G. Box (1979), "On a measure of the lack of fit in time series models", Biometrika, 66, pp. $265-70$.

Mark, N. C. (2001), International Macroeconomics and Finance: Theory and Empirical Methods, Blackwell.

Martin, J. G. (1898), A Century of Finance: Martin's History of the Boston Stock and Money Markets, One Hundred Years, from January 1798 to January 1898, Boston: Privately Published.

Michael, P., Nobay, R. A. and Peel, D. A. (1997) "Transaction Costs And Nonlinear Adjustments In Real Exchange Rates: An Empirical Investigation", Journal Of Political Economy, Vol. 105, No. 4, August 1997, pp. 862-79.

Murray, Christian J. and David H. Papell (2002), "The purchasing power parity persistence paradigm", Journal of International Economics, 56, pp. 1-19.

Murray, Christian J. and David H. Papell (2005), "The purchasing power parity puzzle is worse than you think", Empirical Economics, 30, pp. 783-790.

Officer, Lawrence H. (1983), "Dollar-Sterling mint parity and exchange rates, 17911834", Journal of Economic History, 43, pp. 579-616. 
Officer, Lawrence H. (1985), "Integration in the American foreign exchange market, 1791-1900", Journal of Economic History, 45, 557-585.

Paya, I. and D. Peel (2006), "A New Analysis of the Determinants of the Real DollarSterling Exchange Rate: 1871 - 1994", Journal of Money Credit and Banking, 38(8), December, pp. 1971 - 1990.

Reitz, S. and M. P. Taylor (2008), "The coordination channel of foreign exchange intervention: A nonlinear microstructural analysis", European Economic Review, Vol. 52, pp. $55-76$.

Rogoff, K. (1996), "The Purchasing Power Parity Puzzle", Journal of Economic Literature, 34 , pp. $647-668$.

Rossi, B. (2005), "Confidence Intervals for Half-Life Deviations from Purchasing Power Parity", Journal of Business and Economic Statistics, 23(4), pp. $432-442$

Samuelson, P.A. (1964), "Theoretical notes on trade problems," Review of Economics and Statistics, 46(2), pp. 145-54.

Stock, J. H. (1991), "Confidence Intervals for the Largest Autoregressive Root in U.S. Macroeconomic Time Series", Journal of Monetary Economics, 28, pp. 435 - 459.

Taylor, A. (2001), "Potential Pitfalls for the Purchasing Power Parity Puzzle? Sampling and Specification Biases in Mean Reversion Tests of the Law of One Price", Econometrica, 69, PP. $473-498$.

Teräsvirta, T. (1994) "Specification, Estimation, and Evaluation of Smooth Transition Autoregressive Models", Journal of American Statistics Association, Vol. 89, pp. 208-218.

Warren, G. F. and F.A. Pearson (1933), Prices, New York: John Wiley and Sons.

Working, H. (1960), "Note on the Correlation of First Difference of Averages in a Random Chain", Econometrica, 28, pp. 916 - 918. 
Figure 1. US-UK Real Exchange Rate (Log)

Log US-UK Real Exchange Rate, 1794-2009

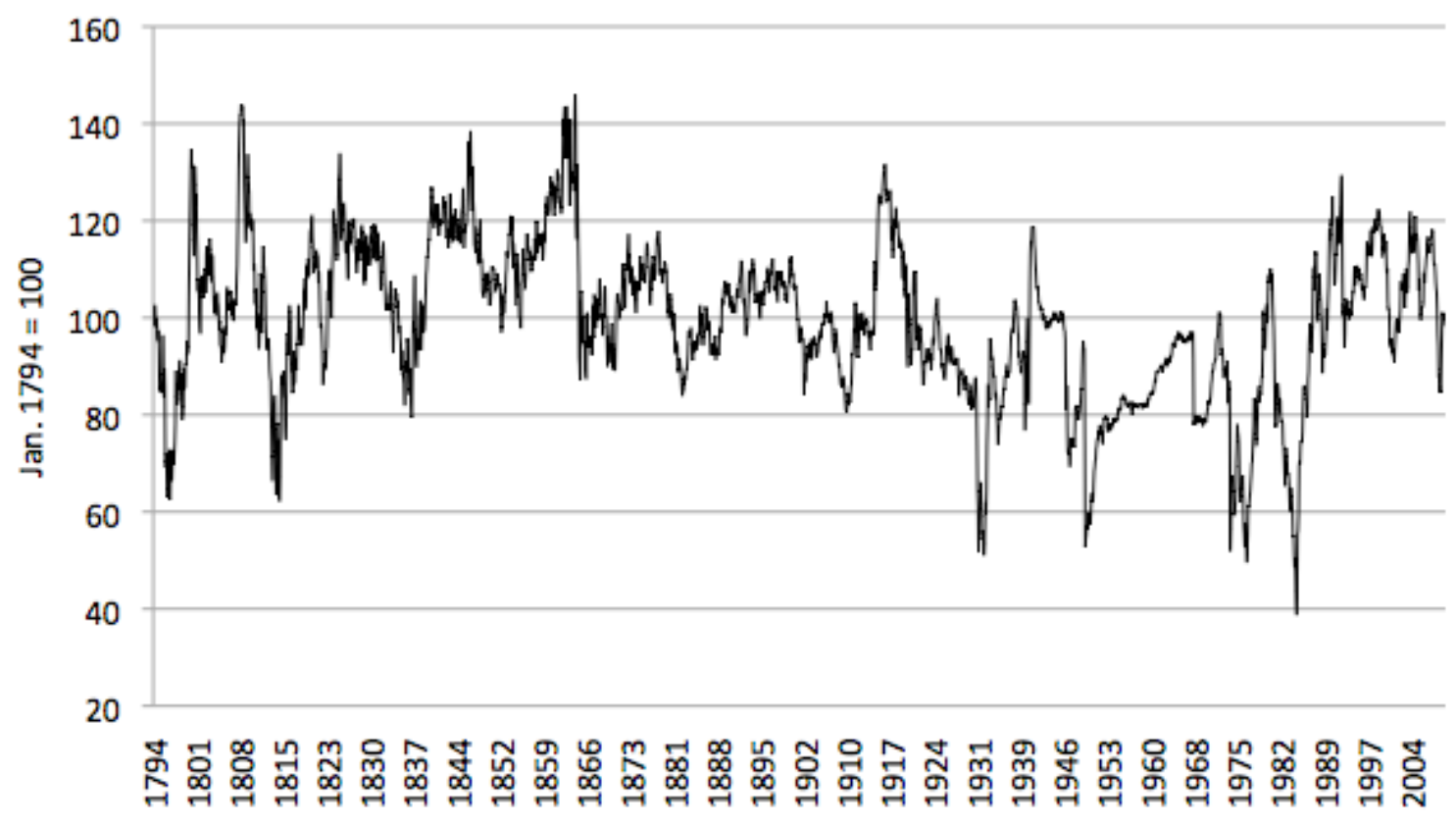

Figure 2. UK-US Trend Real GDP Per Capita, \% Difference UK-US Trend Per Capita Real GDP, 1794-2009

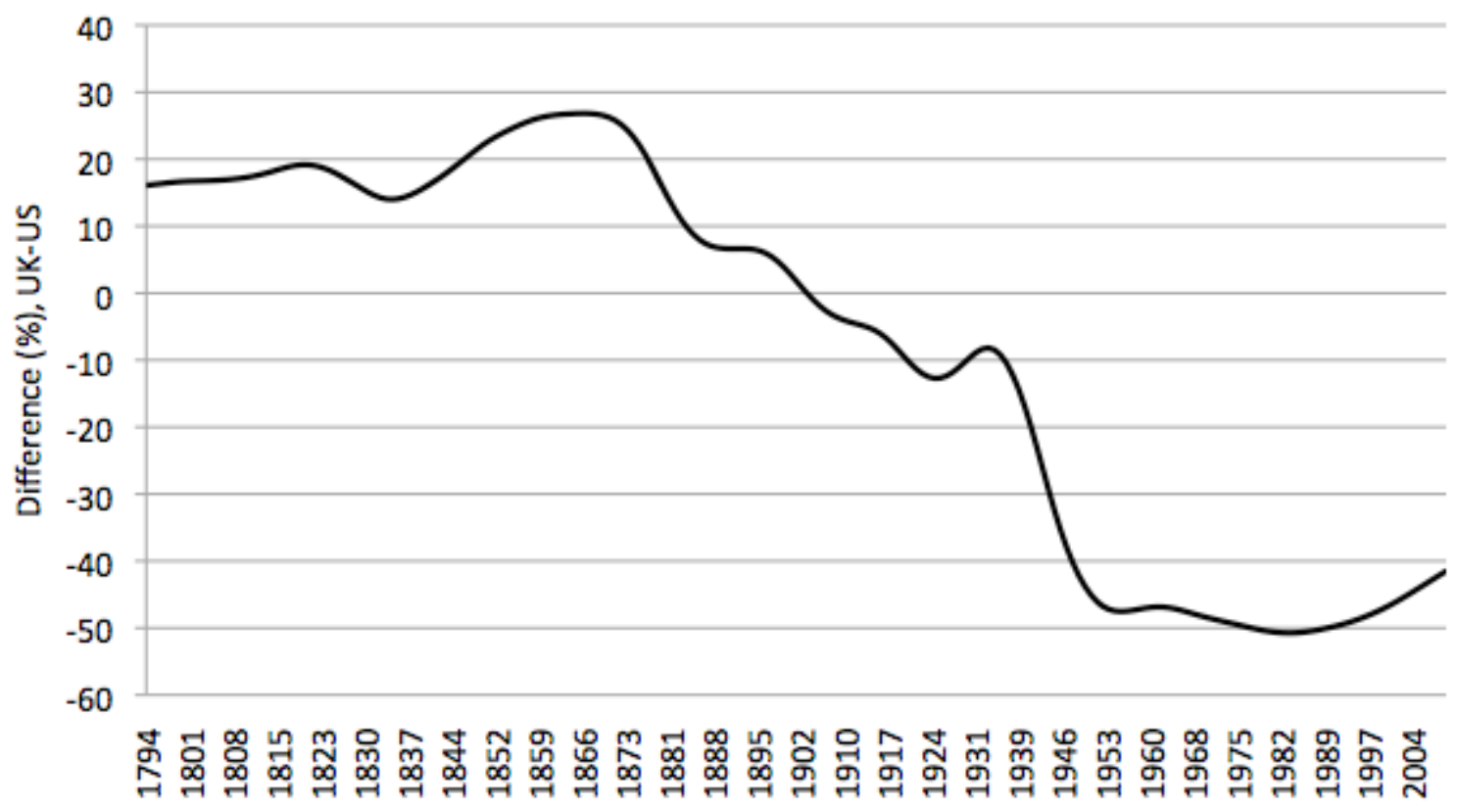


Figure 3: Generalized Impulse Responses of Estimated ESTAR Models
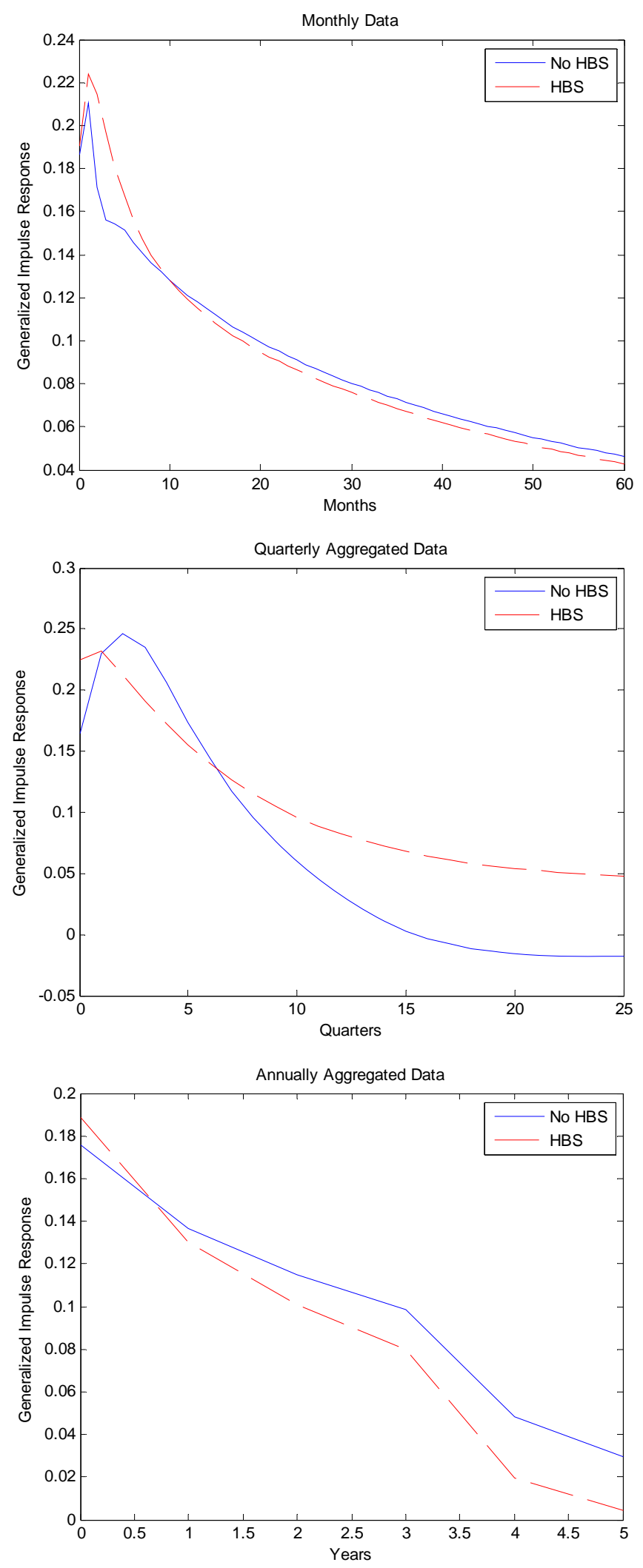
Table 1. AR(1) Model Estimates

\begin{tabular}{|c|c|c|c|c|c|c|}
\hline \multicolumn{7}{|c|}{ Panel A: Estimates of AR(1) regression } \\
\hline Frequency & c & $\rho$ & & $\mathrm{R}^{2}$ & D.-W. & Half-Life (mos.) \\
\hline Monthly & $\begin{array}{c}0.0159 \\
(0.0044)\end{array}$ & $\begin{array}{c}0.9802 \\
(0.0053)\end{array}$ & & 0.9607 & 1.7099 & $\begin{array}{c}34.6 \\
(23.5,65.2)\end{array}$ \\
\hline Quarterly & $\begin{array}{c}0.0393 \\
(0.0103)\end{array}$ & $\begin{array}{c}0.9508 \\
(0.0126)\end{array}$ & & 0.904 & 1.7086 & $\begin{array}{c}41.2 \\
(27.1,83.5)\end{array}$ \\
\hline Annual & $\begin{array}{c}0.13 \\
(0.0322)\end{array}$ & $\begin{array}{c}0.8373 \\
(0.0389)\end{array}$ & & 0.7008 & 1.6586 & $\begin{array}{c}46.84 \\
(30.5,91.6)\end{array}$ \\
\hline \multicolumn{7}{|c|}{ Panel B: Estimates of AR(1) regression with HBS term } \\
\hline Frequency & $\mathrm{c}$ & $\rho$ & $\mu$ & $\mathrm{R}^{2}$ & D.-W. & Half-Life (mos.) \\
\hline Monthly & $\begin{array}{c}0.0198 \\
(0.0044)\end{array}$ & $\begin{array}{c}0.9756 \\
(0.0053)\end{array}$ & $\begin{array}{c}0.0047 \\
(0.0021)\end{array}$ & 0.9608 & 1.7060 & $\begin{array}{c}28.07 \\
(19.6,49.2)\end{array}$ \\
\hline Quarterly & $\begin{array}{c}0.0494 \\
(0.0119)\end{array}$ & $\begin{array}{c}0.9394 \\
(0.0143)\end{array}$ & $\begin{array}{c}0.0117 \\
(0.0058)\end{array}$ & 0.9044 & 1.6990 & $\begin{array}{c}33.24 \\
(22.4,62.9)\end{array}$ \\
\hline Annual & $\begin{array}{c}0.1668 \\
(0.0357)\end{array}$ & $\begin{array}{c}0.795 \\
(0.0427)\end{array}$ & $\begin{array}{c}0.0404 \\
(0.0192)\end{array}$ & 0.7076 & 1.6297 & $\begin{array}{c}36.26 \\
(24.4,64.6)\end{array}$ \\
\hline
\end{tabular}

Note: Heteroskedacticity-robust standard errors for regression coefficients and 95\% confidence intervals for half-life estimates are reported in parentheses. 
Table 2. AR(p) Model Estimates

\begin{tabular}{|c|c|c|c|c|c|c|}
\hline \multirow[b]{2}{*}{ Coefficient } & \multicolumn{3}{|c|}{$\mathrm{AR}(\mathrm{p})$ Estimation } & \multicolumn{3}{|c|}{ AR(p) with HBS Term } \\
\hline & Monthly & Quarterly & Annual & Monthly & Quarterly & Annual \\
\hline Constant & $\begin{array}{c}0.0167 \\
(0.0037)\end{array}$ & $\begin{array}{c}0.0454 \\
(0.0101)\end{array}$ & $\begin{array}{c}0.1562 \\
(0.0329)\end{array}$ & $\begin{array}{c}0.0211 \\
(0.0043)\end{array}$ & $\begin{array}{c}0.0574 \\
(0.0118)\end{array}$ & $\begin{array}{c}0.2078 \\
(0.0371)\end{array}$ \\
\hline$\lambda$ & $\begin{array}{c}0.9791 \\
(0.0046)\end{array}$ & $\begin{array}{c}0.9432 \\
(0.0124)\end{array}$ & $\begin{array}{c}0.805 \\
(0.0399)\end{array}$ & $\begin{array}{c}0.9741 \\
(0.0052)\end{array}$ & $\begin{array}{c}0.9294 \\
(0.0142)\end{array}$ & $\begin{array}{c}0.7455 \\
(0.0446)\end{array}$ \\
\hline$\delta_{1}$ & $\begin{array}{c}0.1582 \\
(0.0303)\end{array}$ & $\begin{array}{c}0.1532 \\
(0.0439)\end{array}$ & $\begin{array}{c}0.1976 \\
(0.0696)\end{array}$ & $\begin{array}{c}0.1604 \\
(0.0304)\end{array}$ & $\begin{array}{c}0.1603 \\
(0.0441)\end{array}$ & $\begin{array}{c}0.2286 \\
(0.0721)\end{array}$ \\
\hline$\delta_{2}$ & $\begin{array}{c}-0.0804 \\
(0.0271)\end{array}$ & & & $\begin{array}{c}-0.0775 \\
(0.0272)\end{array}$ & & \\
\hline$\mu$ & & & & $\begin{array}{l}0.0051 \\
(0.002) \\
\end{array}$ & $\begin{array}{c}0.0138 \\
(0.0058) \\
\end{array}$ & $\begin{array}{c}0.0521 \\
(0.0188) \\
\end{array}$ \\
\hline $\mathrm{p}$ & 3 & 2 & 2 & 3 & 2 & 2 \\
\hline $\mathrm{N}$ & 2592 & 864 & 216 & 2592 & 864 & 216 \\
\hline Durbin-Watson & 2.0011 & 1.9788 & 1.9874 & 2.0007 & 1.9803 & 2.006 \\
\hline$R^{2}$ & 0.9618 & 0.9062 & 0.7142 & 0.9619 & 0.907 & 0.7252 \\
\hline$Q(p)$ & 1.7269 & 5.1888 & 0.2707 & 1.4103 & 4.4083 & 0.1253 \\
\hline$Q^{*}(p)$ & 7.8147 & 5.9915 & 5.9915 & 7.8147 & 5.9915 & 5.9915 \\
\hline
\end{tabular}

Notes:

i) Heteroskedacticity-robust standard errors for regression coefficients and 95\% confidence intervals for half-life estimates, computed by Stock's (1991) method, are reported in parentheses.

ii) Q(p) is the Ljung-Box (1979) test statistic, which is distributed as a $\chi_{(p)}^{2}$ statistic. $Q^{*}(p)$ represents the critical values of the test statistic. 
Table 3. Estimates of half-lives from AR(p) Model

\begin{tabular}{|c|c|c|c|c|c|c|}
\hline \multicolumn{7}{|c|}{ Panel A: Non HBS Results } \\
\hline \multirow[b]{2}{*}{ Frequency } & \multicolumn{3}{|c|}{ GIRF Estimates of $\lambda$-lives } & \multirow[t]{2}{*}{ Half Life ( R ) } & \multirow[t]{2}{*}{ Half Life ( AC ) } & \multirow[b]{2}{*}{$\mathrm{p}$} \\
\hline & $25 \%$ & $50 \%$ & $75 \%$ & & & \\
\hline Monthly & 16.0 & 33.7 & 63.9 & $\begin{array}{c}28.1 \\
(16.538 .6)\end{array}$ & $\begin{array}{c}32.8 \\
(22.858 .0)\end{array}$ & 3 \\
\hline Quarterly & 20.6 & 37.9 & 67.4 & $\begin{array}{c}27.1 \\
(18.747 .8)\end{array}$ & $\begin{array}{c}35.6 \\
(24.6 \quad 62.9)\end{array}$ & 2 \\
\hline Annual & 27.5 & 44.5 & 71.3 & $\begin{array}{c}26.2 \\
(17.845 .7)\end{array}$ & $\begin{array}{c}38.3 \\
(26.167 .0)\end{array}$ & 2 \\
\hline \multicolumn{7}{|c|}{ Panel B: HBS Results } \\
\hline \multirow[b]{2}{*}{ Frequency } & \multicolumn{3}{|c|}{ GIRF Estimates of $\lambda$-lives } & \multirow[t]{2}{*}{ Half Life ( R ) } & \multirow[t]{2}{*}{ Half Life ( AC ) } & \multirow[b]{2}{*}{$\mathrm{p}$} \\
\hline & $25 \%$ & $50 \%$ & $75 \%$ & & & \\
\hline Monthly & 13.1 & 27.2 & 51.4 & $\begin{array}{c}23.1 \\
(16.538 .3)\end{array}$ & $\begin{array}{c}26.4 \\
(18.843 .7)\end{array}$ & 3 \\
\hline Quarterly & 16.8 & 30.4 & 53.7 & $\begin{array}{c}21.3 \\
(15.035 .6)\end{array}$ & $\begin{array}{c}28.4 \\
(20.147 .6)\end{array}$ & 2 \\
\hline Annual & 22.6 & 34.9 & 53.3 & $\begin{array}{c}17.7 \\
(12.4 \quad 28.4)\end{array}$ & $\begin{array}{c}28.3 \\
(19.945 .5)\end{array}$ & 2 \\
\hline
\end{tabular}

Notes:

(i) Half Life ( $R$ ) computes the half life using Rossi's (2005) bias correction procedure

(ii) Half Life (AC) computes the half life based on Andrews (1993) and Andrews and Chen (1994) proposed methods

(iii) Numbers in brackets represent the $95 \%$ confidence intervals computed using Stock's (1991) method 
Table 4. Unit Root Test Statistics

\begin{tabular}{|c|c|c|c|c|c|}
\hline \multirow{2}{*}{ Frequency } & \multicolumn{2}{|c|}{$q_{t}$} & \multicolumn{2}{c|}{ HBS-Adjusted } & \multirow{2}{*}{ 1\% C.V. } \\
\cline { 2 - 5 } & D.F. & P.P. & D.F. & P.P. & \\
\hline Monthly & -5.094 & -5.284 & -5.660 & -5.911 & -3.430 \\
\hline Quarterly & -4.661 & -5.087 & -5.192 & -5.172 & -3.430 \\
\hline Annual & -4.341 & -4.557 & -4.940 & -5.211 & -3.472 \\
\hline
\end{tabular}

Table 5: Results of linearity test and summary of delay parameter selection

\begin{tabular}{|c|c|c|c|c|c|c|}
\hline \multirow[b]{2}{*}{ Model Estimated } & \multicolumn{2}{|r|}{ Monthly } & \multicolumn{2}{|r|}{ Quarterly } & \multicolumn{2}{|r|}{ Annual } \\
\hline & d & Linearity Test & d & Linearity Test & d & Linearity Test \\
\hline No HBS Term & 1 & $0.0621 *$ & 1 & $0.0142^{* *}$ & 4 & $0.0127^{* *}$ \\
\hline HBS Term & 1 & $0.0097 * * *$ & 1 & $0.0426^{* *}$ & 4 & $0.0313^{* *}$ \\
\hline
\end{tabular}

Note: Numbers above are $p$-values from linearity tests; ${ }^{*}=10 \% ;{ }^{* *}=5 \% ; * * *=1 \%$ level of significance 
Table 6: GIRF estimates of Lambda-Life from ESTAR Model (Current Floating Period)

\begin{tabular}{|l|c|c|c|c|c|c|}
\hline \multirow{2}{*}{$\lambda$-life } & \multicolumn{3}{|c|}{ ESTAR model } & \multicolumn{3}{c|}{ ESTAR model with HBS Term } \\
\cline { 2 - 7 } $25 \%$ & Monthly & Quarterly & Annual & Monthly & Quarterly & Annual \\
\hline $50 \%$ & 7.1 & 20.9 & 11.1 & 7.6 & 12.6 & 9.5 \\
$75 \%$ & 22.8 & 27.6 & 32.9 & 19.9 & 24.7 & 26.5 \\
\hline \hline $\mathrm{p}$ & 59.6 & 37.2 & 43.7 & 54.1 & 56.8 & 41.9 \\
$\mathrm{~d}$ & 3 & 4 & 1 & 2 & 2 & 1 \\
$\mathrm{~N}$ & 1 & 3 & 4 & 1 & 1 & 4 \\
& 461 & 154 & 39 & 461 & 154 & 39 \\
\hline
\end{tabular}

